\title{
TRANSCENDENDO A LITERATURA: O CASO DO DR. ANTÔNIO E JOÃO DO RIO NO CINEMA ${ }^{1}$
}

\section{TRANSCENDING LITERATURE: THE CASE OF DR. ANTÔNIO AND JOÃO DO RIO ON SCREEN}

\author{
Carla Helena LANGE ${ }^{2}$ \\ Wellington Ricardo FIORUCI ${ }^{3}$
}

\begin{abstract}
Resumo: Sob a ótica da Intermidialidade e dos Estudos Interartes, este estudo teve como propósito analisar o livro Memórias de um rato de hotel (1912), com autoria atribuída a João do Rio, e a adaptação cinematográfica baseada nesta obra, Muitos homens num só (2015), dirigida por Mini Kerti. O contexto de ambas as obras é o início do século XX, durante o período da Belle Époque brasileira, auge da carreira de João do Rio e do Dr. Antônio, sendo o primeiro pseudônimo de Paulo Barreto e o segundo o de um gatuno que ficou muito famoso por roubar hotéis no Rio de Janeiro. Desta forma, contando com uma metodologia de cunho comparativo e tendo como base as teorias acerca da adaptação, esta pesquisa buscou analisar as relações entre Memórias de um rato de hotel (1912) e Muitos homens num só (2015), além de evidenciar a importância de ambas as obras no contexto literário e cinematográfico.
\end{abstract}

Palavras-chave: João do Rio. Dr. Antônio. Memórias de um rato de hotel. Muitos homens num só. Estudos Interartes.

Abstract: From the perspective of Intermediality and Interart Studies, this study aims to analyze the
book Memórias de um rato de hotel (1912), whose authorship is attributed to João do Rio, and the
cinematographic adaptation based on this work, entitled Muitos homens num só (2015), and directed
by Mini Kerti. The context of both works is the beginning of the $20^{\text {th }}$ century, the period of the
Brazilian Belle Époque, the height of João do Rio's and Dr. Antônio's career; the first is the
pseudonym of Paulo Barreto and the second is the pseudonym of a famous thief known for robbing
hotels in Rio de Janeiro. Thus, through a comparative methodology and based on theories about
adaptation, this research sought to analyze the relationship between Memórias de um rato de hotel
(1912) and Muitos homens num só (2015), besides highlighting the importance of both works in the
literary and cinematographic context.

Keywords: João do Rio. Dr. Antônio. Memórias de um rato de hotel. Muitos homens num só. Interart Studies.

\section{Memórias de um rato de hotel: memórias de João do Rio ou Dr. Antônio?}

Dono de muitos pseudônimos, João Paulo Alberto Coelho Barreto (3 de agosto de 1881, Rio de Janeiro), o popular João do Rio, foi um escritor, jornalista, teatrólogo, tradutor e,

\footnotetext{
${ }^{1}$ Artigo extraído da monografia intitulada $O$ encontro de João do Rio e Dr. Antônio em Memórias de um rato de hotel $e$ Muitos homens num só: diálogos entre cinema e literatura, de autoria de Carla Helena Lange e orientada por Wellington Ricardo Fioruci.

${ }^{2}$ Mestranda do Programa de Pós-graduação em Letras (PPGL) da Universidade Tecnológica Federal do Paraná UTFPR, campus Pato Branco. E-mail: carllahelena@ hotmail.com

${ }^{3}$ Doutor em Letras pela Universidade Estadual Paulista Júlio de Mesquita Filho (UNESP-Assis), na área de Literatura Comparada. Professor no curso de graduação em Letras e do mestrado em Letras (PPGL) da Universidade Tecnológica Federal do Paraná, campus Pato Branco. E-mail: fioruci@utfpr.edu.br Revista Graphos, Vol. 20 n. 1, 2018 | UFPB/PPGL | ISSN 1516-1536
} 
talvez sua característica mais marcante, um carioca apaixonado pelas ruas. Considerado a “[...] flor estilizada da nossa Belle Époque” (RODRIGUES, 2010, p. 271), João do Rio trabalhou em vários jornais (A Tribuna, Gazeta de Notícias, Gazeta), atingindo o auge da sua produção nos primeiros anos do século XX. O interesse pelas ruas da cidade lhe rendeu consideráveis trabalhos como, por exemplo, As religiões do Rio (1905), A alma encantadora das ruas (1910), A mulher e os espelhos (1919), além da obra objeto de estudo do presente trabalho, Memórias de um rato de hotel (1912), entre outros.

De acordo com a biografia João do Rio: vida, paixão e obra (2010), escrita por João Carlos Rodrigues, João do Rio publicou, em julho de 1911, uma crônica um pouco diferente daquelas a que os leitores estavam acostumados a ler no jornal A Notícia. O texto estava no formato de uma carta de um leitor anônimo, que confessava ter assassinado uma prostituta:

\footnotetext{
Depois de dizer que "o verdadeiro assassino mata por prazer (...) para realizar uma obra de arte (...) e um belo crime para ser um belo crime (...) tem como condição essencial ficar impune", o possível criminoso ameaça atirar uma criancinha debaixo de um bonde e ainda posar para imprensa como seu frustrado salvador. Como esse novo crime não aconteceu, pois não foi registrado pela imprensa da época, tudo levava a crer que era mais um capricho de estilo de João do Rio, fã confesso do inglês Thomas De Quincey, autor de $O$ assassinato como uma das belas artes e Memórias de um comedor de ópio (RODRIGUES, 2010, p. 143).
}

Apreciador do gênero policial, João do Rio demonstra interesse em retratar o mundo do crime do século XX, assim como demonstra o excerto acima. Esse interesse se evidencia mais ainda quando João do Rio decide escrever sobre Arthur Antunes Maciel, o famoso Dr. Antônio, que foi preso em Juiz de Fora, no ano de 1911. Dr. Antônio ficou muito conhecido na época por ser um "rato de hotel" que aplicava seus golpes de maneira muito inteligente, sem o uso de violência contra os hóspedes de luxuosos hotéis do Rio de Janeiro, São Paulo, Bahia e Minas Gerais. Evidentemente, esse fato chamou a atenção de Paulo Barreto e o motivou a escrever o artigo "O representativo do roubo inteligente", publicado no jornal A Notícia, em 20 de agosto de 1911, no qual ele exalta a personalidade de Dr. Antônio, comparando-o ao famoso ladrão dos folhetins franceses, Arsène Lupin:

Como é possível que um país entre no concerto da civilização sem ter um grande gatuno representativo, mas gatuno mesmo, só gatuno, campeão de apanhar o alheio contra a vontade do possuidor? E nós não o tínhamos, a não ser talvez o Dr. Antônio, que, aliás, está para Arsène Lupin como a Avenida Central está para a linha dos boulevards ou para Oxford street. O Dr. Antônio possuía topete e calma. Era elegante, era bem-falante, era um sportsman da caça de carteiras verdadeiramente razoável. Aprecia nos melhores lugares, tranquilamente.

Operava com um sangue-frio digno dos melhores aplausos. Mantinha vivaz a inteligência.

Revista Graphos, Vol. 20 n. 1, 2018 | UFPB/PPGL | ISSN 1516-1536 
Lembro-me que um dia mostraram-mo na rua do Ouvidor.

- É aquele o Dr. Antônio!

Olhei-o com respeito e carinho. Só o saber que enganava os outros, sem que a polícia pudesse prender, dava-lhe uma auréola de superioridade mental (RIO, 2015, p. 177$)^{4}$.

Esse encantamento de João do Rio pela história do Dr. Antônio vai um pouco além. Após a publicação do artigo sobre o famoso gatuno, ele escreveu mais duas crônicas relacionadas ao mundo policial: "O assassino volta a escrever-me" e "O assassino visita-me", para, então, na véspera do natal daquele ano, publicar no jornal Gazeta o primeiro capítulo do folhetim Memórias de um rato de hotel: o Dr. Antonio narra a sua vida ${ }^{5}$ o qual teve duração de cerca de dois meses. Apesar de o nome de Paulo Barreto não aparecer nenhuma vez no folhetim, vários indícios do próprio texto levam a crer que a autoria é realmente do cronista carioca, como, por exemplo, o fato de o gatuno confessar, logo nas primeiras páginas, que nunca foi um bom leitor: "Nunca fui dado à literatura e à fantasia, sendo muito limitado o número de livros que tenho lido. Escrever memórias não seria coisa que me passasse pela imaginação em hipótese alguma" (RIO, 2015, p. 13).

Outrossim, há na narrativa trechos do artigo escrito por João do Rio, "O representativo do roubo inteligente": "Lembro-me que um dia mostraram-mo na rua do Ouvidor. - É aquele o Dr. Antônio! Olhei-o com respeito e carinho. Só o saber que enganava os outros, sem que a polícia pudesse prender, dava-lhe uma auréola de superioridade mental" (RIO, 2015, p. 1415). Além disso, também há várias citações de autores consagrados pela literatura, como Dante Alighieri, Alexandre Dumas, Johann Wolfgang Von Goethe, entre outros: "Bem se pode escrever na Detenção o verso de Dante: Lasciate ogni speranza ó voi che entrate!" (RIO, 2015, p. 101); "Mas, no silêncio frio do cárcere, na escura galeria, tal qual como no Conde de Monte Cristo (de tal forma a vida é um romance!), proibidos de falar, proibidos de conversar, nós falávamos, a princípio com sinais sonoros, batendo nos muros, depois, baixo, sem nos vermos" (RIO, 2015, p. 109); “O quanto as mulheres têm poder sobre mim! Por elas fui forçado a encontrar a alma danada do "Dr. Antônio". Só por uma delas, eu, como o Fausto, não entraria no inferno, para a fúria de Mefistófeles” (RIO, 2015, p. 162).

Logo, a história desse personagem do crime brasileiro encantou não só João do Rio, mas também seu público leitor. Esse encantamento imediato fez com que, apenas três semanas

\footnotetext{
${ }^{4} \mathrm{O}$ excerto acima foi retirado dos anexos da terceira edição do livro Memórias de um rato de hotel, publicado pela Dantes Editora em 2015.

${ }^{5} \mathrm{O}$ primeiro capítulo do folhetim Memórias de um rato de hotel: o Dr. Antonio narra a sua vida está disponível em: <http://memoria.bn.br/DocReader/DocReader.aspx?bib=103730_04\&pesq=rato\%20de\%20hotel>. Acesso em: 20 jul. 2018.
}

Revista Graphos, Vol. 20 n. 1, 2018 | UFPB/PPGL | ISSN 1516-1536 
depois da publicação do último capítulo na Gazeta, o folhetim fosse editado em volume, em março de 1912 (RODRIGUES, 2010). Ainda assim, essas memórias ficaram perdidas ao longo dos anos, tendo sido recuperadas pela Dantes Editora apenas no ano 2000, oitenta e oito anos depois de sua primeira edição. A edição atual conta com uma nota editorial de Cesar Burgos, na qual ele explica como o livro foi resgatado por Plínio Doyle, que ficou surpreso ao perceber uma anotação manuscrita de Francisco Prisco dizendo que João do Rio era o verdadeiro autor das Memórias de um rato de hotel. Faz parte desta edição, como um epílogo, o artigo "O representativo do roubo inteligente", publicado por João do Rio no jornal $A$ Notícia, em 1911. Em 2015, ano de lançamento do filme Muitos homens num só, inspirado na obra, foi lançada a terceira edição do livro, pela mesma editora.

Nesse sentido, é bem verdade que o célebre Dr. Antônio existiu fora da narrativa de João do Rio e, como o próprio narrador de Memórias de um rato de hotel afirma, "O Dr. Antônio nasceu com a República” (RIO, 2015, p. 30). Oriundo de uma boa família de Porto Alegre, Rio Grande do Sul, Arthur Antunes Maciel entrou para a vida do crime em sua cidade natal, porém, após ser expulso de casa por seu pai, nunca mais retornou para a cidade onde nasceu, assim como nunca mais viu sua família. Dessa maneira, o gatuno chegou às ruas do Rio de Janeiro no final de novembro de 1889.

De fato, Arthur Maciel ficou famoso pela alcunha de Dr. Antônio (nome que, aliás, utilizou uma única vez, durante um golpe no hotel Carson's), que era conhecido como “[...] um dandy tranquilo, com um anel de médico no anular; o sorriso no lábio tranquilo [...]" (RIO, 2015, p. 32). Contudo, esse não era o único pseudônimo utilizado pelo gatuno; ele também deu vida a Arthur Barcelos, Júlio Dória, Antenor Guimarães, Júlio Guedes, entre muitos outros. Ele era "Vinte homens num só", conforme o título do capítulo VI de Memórias de um rato de hotel sugere.

No entanto, o que diferenciava o Dr. Antônio dos demais gatunos da época era seu método. O ladrão nunca usou uma chave falsa, nunca violou uma porta e nem mesmo usou qualquer disfarce. As memórias contam que Arthur aprendeu a roubar quando ainda estava no Rio Grande do Sul, com Júlio Charuteiro, um rato de hotel que fazia parte de uma quadrilha de Montevidéu:

O meu processo era o ensinado pelo Júlio Charuteiro, com o aperfeiçoamento de uma inteligência aguçada e preparada. Entrava, via a porta aberta, retirava as joias, a carteira, e ia deitar noutro hotel, perfeitamente calmo. Às vezes ficava no mesmo. Quantas vezes o criado acordava-me com o café.

- V. Ex ${ }^{a}$ não sabe?

- Que há? 
- Houve hoje um roubo aqui.

- Que me diz?

- Entraram no 25.

- Muita coisa?

- O hóspede diz que foi muito.

Fiz-me roubado duas ou três vezes, em vários sítios, preparando adrede o cenário. Os gerentes vinham loucos. Eu mostrava-lhe valises cortadas, o bolso sem o relógio (RIO, 2015, p. 33-34).

Dr. Antônio agia dessa forma, com muita tranquilidade e calma. Com todo o glamour da Belle Époque carioca, o dândi aplicava golpes inteligentíssimos apenas em hotéis de luxo, enquanto se envolvia com muitas mulheres e frequentava os melhores teatros e cafés, portanto, conforme as memórias afirmam: "Só me sinto bem ao lado de gente de posição social" (RIO, 2015, p. 37).

Logo no início do primeiro capítulo, o narrador das memórias do Dr. Antônio conta que Arthur Antunes Maciel não foi preso apenas uma única vez e, em uma de suas prisões, um jornalista foi até a casa de detenção para entrevistar o famoso Dr. Antônio, com a intenção de que o ladrão contasse a história de sua vida para o jornal no qual ele trabalhava. Em seguida, aparece na narrativa trechos do artigo de João do Rio, no qual ele exalta a personalidade do rato de hotel. Então, Arthur Antunes Maciel dá espaço para o Dr. Antônio e decide contar suas peripécias para o público:

\footnotetext{
O público, lendo a verdade a meu respeito, contada por mim mesmo, verá que esse grande bandido, tirando o ato considerado crime pela sociedade, é um homem como qualquer outro, exatamente igual ou talvez melhor, e às vezes menos criminoso que outros sujeitos até depois de mortos respeitados.

Não digo isso para fazer galeria. Digo a verdade, e meta cada um a mão na consciência e veja se no descalabro social um rato de hotel é tão digno de culpa.

- Além do mais, acrescentou o homem do jornal na manhã seguinte, você foi o nosso primeiro rato de hotel. É preciso escrever suas memórias!

- Pois escreva.

- Por que não escreve você?

- A mão treme. Sente-se, que eu dito.

E assim, durante dias, fui ditando e escrevendo o que se vai ler (RIO, 2015, p. 16).
}

Conquanto, se a ideia de Arthur era se redimir diante do público, ele não conseguiu fazer isso em tempo, pois faleceu na casa de detenção, em 1912, com quarenta e sete anos. E o que restou foram as memórias desse gatuno, que finalizam com a notável frase: "Que homem interessante eu fui! Que interessante eu sou!” (RIO, 2015, p. 174).

\section{As máscaras narrativas do texto}


As Memórias de um rato de hotel passam uma falsa ideia de autobiografia, haja vista que o autor (João do Rio) constrói um discurso sobre uma personalidade, um ladrão de hotel do século passado (Dr. Antônio), sob a ótica de um narrador que é o dono dessa personalidade (Arthur Antunes Maciel). Isto é, há no romance Memórias de um rato de hotel uma emulação do gênero autobiografia, pois apesar de o romance passar a ideia de que o autor das memórias é o próprio Dr. Antônio, quem escreve essas memórias e faz esse jogo com o leitor é João do Rio.

Em seu livro O pacto autobiográfico: de Rousseau à internet (2014), Philippe Lejeune faz uma abordagem contemporânea da autobiografia, não apenas como um gênero literário, mas também como um fato cultural. Por conseguinte, a definição de autobiografia seria: "Narrativa retrospectiva em prosa que uma pessoa real faz de sua própria existência, quando focaliza sua história individual, em particular de sua personalidade" (LEJEUNE, 2014, p 16, grifo nosso). Há de se dizer, também, que a autobiografia transita naturalmente entre outros gêneros da literatura íntima, como as memórias. Sendo assim, em Memórias de um rato de hotel, o leitor não vai encontrar um relato da vida de Arthur Antunes Maciel (uma pessoa real, com um registro de identidade real), mas sim de sua personalidade de gatuno, assumida pela identidade de Dr. Antônio.

No entanto, de acordo com a definição proposta por Lejeune, se a autobiografia é uma narrativa na qual uma pessoa real faz uma retrospectiva de sua própria vida, como poderia ser João do Rio o autor de Memórias de um rato de hotel? De fato, João do Rio pode até não ter assinado a obra, conforme mencionado na seção anterior, entretanto, o próprio texto pode comprovar sua autoria. Dado que no discurso escrito é a assinatura que indica o enunciador, Lejeune destaca que os problemas da autobiografia estão relacionados com o nome próprio:

\footnotetext{
Nos textos impressos, a enunciação fica inteiramente a cargo de uma pessoa que costuma colocar seu nome na capa do livro e na folha de rosto, acima ou abaixo do título. É nesse nome que se resume toda a existência do que chamamos de autor [...]. Um autor não é uma pessoa. É uma pessoa que escreve e publica. Inscrito, a um só tempo, no texto e no extratexto, ele é a linha de contato entre eles. O autor se define como sendo simultaneamente uma pessoa real socialmente responsável e o produtor de um discurso (LEJEUNE, 2014, p. 26-27, grifos do autor).
}

Desta forma, pode-se perceber que nas Memórias de um rato de hotel acontece um grande jogo do autor com o leitor, o uso de máscaras narrativas que camuflam, mas não excluem, a relação de identidade entre o autor, o narrador e o personagem, proposta por Lejeune. Ou seja, João do Rio é o autor das memórias, foi ele quem as escreveu, no entanto, ele constrói o texto a partir de um mascaramento narrativo na medida em que constitui Arthur 
Antunes Maciel como o narrador de suas próprias memórias, e traz como personagem principal o Dr. Antônio, sua outra personalidade. Tem-se aqui a relação de João do Rio (autor) versus Arthur Antunes Maciel (narrador) versus Dr. Antônio (personagem).

Apesar disso, o nome "Dr. Antônio" aparece na capa e na folha de rosto do livro; inclusive, na folha de rosto da primeira edição do livro e no folhetim, o título do livro era: Memórias de um "rato de hotel": o Dr. Antônio narra a sua vida. O fato de João do Rio não ter assinado essa obra se deve, talvez, ao interesse de ele querer caracterizá-la como uma autobiografia e não como um romance autobiográfico, haja vista que o texto deixa claro que quem escreveu as memórias não foi Arthur Antunes Maciel, muito menos o Dr. Antônio, pois fica evidente que há modulações discursivas que caracterizam essa obra como de João do Rio. Basta lembrar o momento das Memórias de um rato de hotel em que um jornalista, a cujo nome o leitor não tem acesso, mas supõe-se que seja João do Rio, visita o Dr. Antônio na casa de detenção e pede para que ele conte a história de sua vida para seu jornal: “- Meu caro, não me engano e peço que não me desiluda. Considero você um homem inteligente, fora do comum. Se resolver negar o que está provado em vinte anos de jornais, como um simples batedor de carteira, ficarei muito triste" (RIO, 2015, p. 14, grifo nosso). Logo em seguida, Arthur "relembra" e cita um trecho do artigo que João do Rio escreveu a seu respeito, no qual ele exalta sua inteligência e o compara com Arsène Lupin, conforme foi visto na seção anterior.

Se a definição de autobiografia é uma narrativa em que uma pessoa real faz um retrospecto de sua própria vida, o que seria um romance autobiográfico? A fim de trazer uma definição para o termo "romance autobiográfico", Lejeune diz o seguinte:

\footnotetext{
Chamo assim todos os textos de ficção em que o leitor pode ter razões de suspeitar, a partir das semelhanças que acredita ver, que haja identidade entre autor e personagem, mas que o autor escolheu negar essa identidade ou, pelo menos, não afirmá-la. Assim definido, o romance autobiográfico engloba tanto narrativas em primeira pessoa (identidade do narrador e do personagem) quanto narrativas "impessoais" (personagens designados em terceira pessoa); ele se define por seu conteúdo (LEJEUNE, 2014, p. 29, grifo do autor).
}

O romance autobiográfico se aproxima muito da autobiografia, porém, na autobiografia não há um jogo por detrás das identidades, jogo esse que acontece o tempo todo em Memórias de um rato de hotel, tanto no nível diegético (o problema da dupla personalidade: Arthur versus Dr. Antônio) quanto no nível extradiegético (a questão da autoria do texto: Arthur/Dr. Antônio versus João do Rio). Todavia, para que isso ocorra, de acordo com 
Lejeune (2014), é preciso que o pacto autobiográfico seja firmado, ou seja, deve haver uma afirmação da identidade do nome autor no texto. Existem várias formas de firmar esse pacto, contudo, essas formas têm a finalidade de honrar sua assinatura. Caso a identidade não seja confirmada, como é o caso do romance autobiográfico, o leitor deverá estabelecer semelhanças, independentemente do que diz o autor.

Sendo assim, levando em consideração as propostas de Lejeune, o pacto presente em Memórias de um rato de hotel é o romanesco-autobiográfico: romanesco porque a personagem tem nome diferente do autor, tem-se a relação Dr. Antônio versus João do Rio; autobiográfico porque a personagem tem o mesmo nome do autor e aqui não há uma contradição com a afirmação anterior; acontece que o nome do autor que aparece na capa do livro é o mesmo nome do personagem, Dr. Antônio, pois o verdadeiro autor (João do Rio) omitiu sua identidade da obra, para que essa emulação do gênero autobiografia fosse construída.

Sob essa perspectiva, tais questões de identidade presentes ao longo de todo o livro Memórias de um rato de hotel refletem a fragmentação do sujeito, principalmente de Arthur Antunes Maciel, que assume várias identidades para atingir seus objetivos. Em seu ensaio “Quem precisa da identidade?", Stuart Hall ressalta o seguinte sobre o termo “identidade”:

[...] as identidades são as posições que o sujeito é obrigado a assumir, embora "sabendo" (aqui, a linguagem da filosofia da consciência acaba por nos trair), sempre, que elas são representações, que a representação é sempre construída ao longo de uma "falta", ao longo de uma divisão, a partir do lugar do Outro e que, assim, elas não podem, nunca, ser ajustadas - idênticas - aos processos de sujeito que são nelas investidos. (HALL, 2004, p. 112).

Desta forma, no decorrer da narrativa de Memórias de um rato de hotel, Arthur reconhece que como sujeito ele assume outras identidades, as quais ele chama de "Dr. Antônio", mesmo só tendo usado esse nome em um único golpe: "Eu, Arthur Maciel, não tenho desejo algum mal [sic] e sou muito fraco. O "Dr. Antônio" é que é o Satanás. Ora, esse malandro faz meu corpo agir sempre como em hipnose, pela força de sua vontade. É ele quem faz tudo" (RIO, 2015, p. 90). Assim, Arthur tinha noção das identidades que ele precisava assumir para cometer os crimes e as distinguia de sua própria identidade, deixando claro que ele assumia a identidade do Dr. Antônio sempre quando precisava "trabalhar": "Eu consegui ir para um hotel barato. Mas o "Dr. Antônio" que tenho dentro de mim, andava de chapéu alto, luvas e só de carro. Teria "trabalhado" [...]? Com certeza. Mas coisas sem 
importância. Porque o "Dr. Antônio" não está bem quando um dia deixa de exercitar-se" (RIO, 2015, p. 154).

Em vista disso, a identidade do Dr. Antônio pode ser entendida “[...] ao longo de toda sua história, como pontos de identificação e apego apenas por causa de sua capacidade para excluir, para deixar de fora, para transformar o diferente em "exterior", em objeto" (HALL, 2004, p. 110, grifo do autor). Isto é, a identidade do Dr. Antônio era um ponto de identificação para época, ele era um famoso rato de hotel, certamente não o único, mas o gatuno que se tornou referência para seu tempo.

Para Lejeune (2014), a identidade é definida a partir de três termos: (1) autor, (2) narrador e (3) personagem, sendo que "[n]arrador e personagem são as figuras às quais remetem, no texto, o sujeito da enunciação e o sujeito do enunciado. $\mathrm{O}$ autor, representado na margem do texto por seu nome, é então o referente ao qual remete, por força do pacto autobiográfico, o sujeito da enunciação" (LEJEUNE, 2014, p. 42). Afirma-se aqui, novamente, o que foi dito no início desta seção, a relação de identidade entre João do Rio (autor), Arthur Maciel (narrador) e Dr. Antônio (personagem), forma o pacto firmado entre Arthur Maciel e João do Rio: respectivamente, contar e escrever a história do Dr. Antônio; e o pacto de João do Rio com o leitor, que é firmado por meio de um jogo entre autor e personagem.

Por fim, pode-se dizer que Memórias de um rato de hotel foi escrito em colaboração, pois " [...] o esforço da memória e o esforço da escrita são obras de pessoas diferentes, dentro de um processo de diálogo que poderá deixar vestígios orais e escritos" (LEJEUNE, 2014, p. 138). Desta maneira, Lejeune divide teoricamente o trabalho de escrita em colaboração:

\footnotetext{
- $\mathrm{O}$ modelo tem por função dizer o que sabe e responder às perguntas, ficando, portanto, nessa etapa, isento de responsabilidade. Só pelo fato de ser o outro que escuta, anota, pergunta, e deve assumir mais tarde a responsabilidade de composição do texto, o modelo se vê reduzido ao estado de fonte. Pode se deixar levar pela memória, uma vez que está liberado das restrições ligadas à comunicação escrita. - O redator se vê, ao contrário, incumbido de todas as funções de estruturação, de regência, de comunicação como exterior. [...] Condensar, resumir, eliminar os resíduos, escolher os eixos da pertinência, estabelecer uma ordem, uma progressão. Mas também escolher um modo de enunciação, um tom, um certo tipo de relação com o leitor, elaborar a instância que diz - ou parece escrever - "eu" (LEJEUNE, 2014, p. 138-139, grifo do autor).
}

Tem-se aqui, então, o modelo, Arthur Maciel, que fica incumbido de recorrer às suas memórias para contar a história do Dr. Antônio, mas que não assume nenhuma responsabilidade em relação à escrita. E João do Rio, o redator que fica responsável por 
estruturar e modular a narrativa e que, também, teve a iniciativa de dar origem a essa história que talvez não existisse se não fosse a sua intervenção, por isso, ele "[...] se apresenta como mediador entre dois mundos, quase como um explorador. Sua presença deve ser flagrante e seu estatuto é o de verdadeiro autor [...]" (LEJEUNE, 2014, p. 150, grifo nosso).

Mediante o exposto até aqui, foi possível notar a relação existente entre João do Rio e Dr. Antônio. Dessa forma, a fim de cumprir os objetivos deste trabalho, serão discutidos a seguir os principais conceitos relacionados aos Estudos Interartes, com foco na adaptação cinematográfica.

\section{Estudos interartes: relações entre cinema e literatura}

Os Estudos Interartes são considerados uma área de pesquisa ligada aos estudos de Literatura Comparada, que tem como objetivo, conforme sua denominação, analisar as relações entre literatura e outras artes. Claus Clüver (2006), um dos mais relevantes estudiosos acerca do tema, afirma que nos Estudos Interartes sempre serão as relações transmidiáticas que determinarão as questões inerentes aos objetos de pesquisa. Sendo assim, o autor reconhece a relação entre Literatura Comparada e interartes:

\footnotetext{
Segundo apontam os manuais, a Literatura Comparada tem tradicionalmente a tarefa de se ocupar, sobretudo, de relações textuais. Isso vale também para os Estudos Interartes. E, se for verdade que o Comparativismo não compara nem mais, nem de forma diferente, do que os Estudos Literários (embora às vezes trate de outros objetos ou tenha outros interesses), isso também acontece, mutatis mutandis, com os Estudos Interartes, apesar de que, neste campo, a comparação explícita assume um papel mais acentuado (CLÜVER, 2006, p. 14).
}

A Literatura Comparada é uma disciplina que consiste, basicamente, em estudar as relações entre textos e, para isso, utiliza-se de vários métodos, dentre eles o comparativo. Seguindo nessa perspectiva, Tania Franco Carvalhal (1998) defende que a tarefa de comparar é um hábito de diversas áreas do saber humano; desse modo, a comparação dentro da Literatura Comparada não se dá pelo procedimento de comparar em si, mas sim "[...] como um recurso analítico e interpretativo, a comparação possibilita a esse tipo de estudo literário uma exploração adequada de seus campos de trabalho e o alcance dos objetivos a que se propõe" (CARVALHAL, 1998, p. 7).

Seguindo nessa linha, a pesquisadora chega ao conceito de intertextualidade, concebido por Julia Kristeva em 1969. O termo foi criado a fim de denominar “[...] o processo de 
produtividade do texto literário[...]", essa produtividade textual existe porque, conforme aponta Kristeva, “[...] todo texto é absorção e transformação de outro texto" (KRISTEVA apud CARVALHAL, 1998, p. 50).

Contudo, o conceito de intertextualidade vai além da literatura e foi reconhecido pelos Estudos Interartes como algo que também significa Intermidialidade, visto que o termo "intertextualidade" não vale somente para textos literários e verbais, pois, em se tratando de obras que, independentemente do código estético (artes plásticas, teatro, cinema, etc.), “[...] representam aspectos da realidade sensorialmente apreensível, sempre existe nos processos intertextuais de produção e recepção textual um componente intermidiático - tanto para a Literatura quanto, frequentemente, nas outras artes" (CLÜVER, 2006, p. 14-15).

Com efeito, é no campo dos estudos semiológicos que as relações entre a literatura e outras artes se encontram. Sendo assim, Julio Plaza (2010) explica que a Tradução Intersemiótica teve sua origem com base nos estudos de Roman Jakobson e é definida como um "[...] tipo de tradução que 'consiste na interpretação dos signos verbais por meio de sistemas de signos não verbais', ou 'de um sistema de signos para outros, por exemplo, da arte verbal para a música, a dança, o cinema ou a pintura' [...]” (JAKOBSON apud PLAZA, 2010, p. XI). Em outras palavras, a Tradução Intersemiótica é mais um dos termos utilizados para designar as relações entre as diversas linguagens como, por exemplo, a literária e a cinematográfica, foco deste estudo monográfico.

Outrossim, o estudo das relações entre cinema e literatura não se restringe à atualidade. Em meados da década de 1950, André Bazin, um dos primeiros grandes pensadores do cinema, foi na contramão dos demais críticos da época e já se mostrava favorável às relações entre o cinema e as outras artes. Em 1958, Bazin lançou a série Qu'est-ce que le cinema? (O que é o cinema), a qual reúne artigos críticos sobre cinema, mas que, conforme o próprio autor afirma no prefácio, não traz a resposta para a pergunta do título. Um dos artigos que compõem essa série de livros é "Por um cinema impuro: defesa da adaptação", no qual ele defende a adaptação, opondo-se aos críticos da época que buscavam um cinema "puro". O crítico de cinema francês considera que o cinema é uma arte relativamente nova em relação às outras artes, por isso é inevitável que as artes mais antigas exerçam influência sobre o cinema:

Se o cinema tivesse dois ou três milhões de anos, sem dúvida veríamos mais claramente que ele não escapa às leis comuns da evolução das artes. Mas ele só tem 60 anos e as perspectivas históricas estão prodigiosamente esmagadas. O que se estende normalmente numa duração de uma ou duas civilizações, reduz-se aqui numa vida humana. E isso não é a principal causa de erro, pois essa evolução acelerada não é de modo algum contemporânea à das outras artes. O cinema é 
jovem, mas a literatura, o teatro, a música e a pintura são tão velhos quanto a história (BAZIN, 1991, p. 84).

Nesse sentido, Bazin sai em defesa do cinema, pois não o considera uma arte inferior às demais simplesmente pelo fato de ser tão jovem. Contudo, esse pensamento de Bazin era considerado de vanguarda à sua época, pois, no período em que escrevia, a crítica era desfavorável à adaptação, haja vista que esta era considerada "[...] como o quebra-galho mais vergonhoso pela crítica moderna [...]” (BAZIN, 1991, p. 84). Em oposição a essa visão, o autor estimula o diálogo entre o cinema, a literatura e o teatro, não categorizando o cinema como uma arte "pura", pois, de acordo com o próprio:

O que provavelmente nos engana no cinema, é que, ao contrário do que ocorre
geralmente num ciclo evolutivo artístico, a adaptação, o empréstimo, a imitação não
parecem situar-se na origem. Em contrapartida, a autonomia dos meios de
expressão, a originalidade dos temas nunca foram tão grandes quanto nos primeiros
25 ou 30 anos do cinema. Podemos admitir que uma arte nascente tenha procurado
imitar seus primogênitos, para depois manifestar pouco a pouco suas próprias leis e
temas; mas não compreendemos bem que ela ponha uma experiência cada vez maior
a serviço de obras alheias a seu talento, como se essas capacidades de invenção, de
criaçãa específica estivessem em razão inversa de seus poderes de expressão
(BAZIN, 1991, p. 85).

Em vista disso, apesar de a crítica da época não ser favorável às adaptações cinematográficas, os filmes adaptados de romances, principalmente os clássicos, só foram crescendo, até ganharem boa parte da indústria cinematográfica. Consequentemente, com todo esse crescimento das adaptações no mercado cinematográfico, a noção de fidelidade - que se opõe ao princípio intertextual - começou a ser questionada. Nessa perspectiva, Julio Plaza (2010) defende que a Tradução Intersemiótica é fundamentalmente contrária à ideologia de fidelidade, haja vista que:

[...] numa tradução intersemiótica, os signos empregados têm tendência a formar novos objetos imediatos, novos sentidos e novas estruturas que, pela sua própria característica diferencial, tendem a se desvincular do original. [...] A tradução intersemiótica induz, [...] à descoberta de novas realidades, visto que "na criação de uma nova linguagem não se visa simplesmente uma outra representação de realidades ou conteúdos já pré-existentes em outras linguagens, mas a criação de novas realidades, de novas formas-conteúdo" (PLAZA, 2010, p. 30, grifo nosso).

Com efeito, pode-se dizer que é justamente isso que acontece na adaptação cinematográfica, em que a linguagem fílmica, por possuir recursos próprios ao seu código, pode (re)criar cenas que a linguagem literária não permitiria, assim como há códigos da linguagem literária que se limitam ao serem transpostos para a linguagem fílmica. Seguindo 
nessa linha, Robert Stam também defende a ideia de que a adaptação cinematográfica cria uma situação em relação à obra de partida ${ }^{6}$. O autor afirma que “[...] a adaptação cinematográfica cria uma nova situação áudio-visual-verbal, mais do que meramente imitar o velho estado de coisas como representado pelo romance original. A adaptação assim molda novos mundos mais do que simplesmente retrata/trai mundos antigos." (STAM, 2006, p. 26).

Seguindo nessa mesma linha de pensamento, Linda Hutcheon, em Uma teoria da adaptação, afirma que "[a] adaptação é repetição, porém repetição sem replicação" (2013, p. 28). Com efeito, para a autora, falar de adaptação pode ser mais complexo do que parece, pois o problema está na definição do termo, uma vez que a mesma palavra é usada tanto para o processo quanto para o produto: “Como produto é possível dar a adaptação uma definição formal; como um processo de criação e de recepção, por outro lado, é necessário levar em consideração outros aspectos" (HUTCHEON, 2013, p. 39).

Primeiramente, deve-se levar em consideração que os adaptadores são intérpretes, antes de serem criadores, e, independente do motivo, “[...] a adaptação, do ponto de vista do adaptador, é um ato de apropriação ou recuperação, e isso sempre envolve um processo duplo de interpretação e criação de algo novo" (HUTCHEON, 2013, p. 45). Desta forma, "Para o leitor, espectador ou ouvinte, a adaptação como adaptação é inevitavelmente um tipo de intertextualidade se o receptor estiver familiarizado com o texto adaptado" (HUTCHEON, 2013, p. 45, grifos da autora). Consequentemente, a adaptação deve ser considerada híbrida:

\begin{abstract}
A adaptação, também, deste ponto de vista, pode ser vista como uma orquestração de discursos, talentos e trajetos, uma construção "híbrida", mesclando mídia e discursos, um exemplo do que Bazin na década de 1950 já chamava de cinema "misturado" ou "impuro". A originalidade completa não é possível nem desejável. E se a "originalidade" na literatura é desvalorizada, a "ofensa" de "trair" essa originalidade, através de, por exemplo, uma adaptação "infiel”, é muito menos grave (STAM, 2006, p. 23)
\end{abstract}

Em vista disso, pode-se verificar, conforme as recomendações dos teóricos apresentados ao longo deste capítulo, que não se deve buscar somente semelhanças ou equivalências nas adaptações, pois as diferenças, os acréscimos e os cortes também fazem parte da obra de chegada. Portanto, as adaptações devem ser vistas e julgadas como adaptações.

\footnotetext{
${ }^{6}$ Serão utilizados os termos "obra de partida" e "obra de chegada", presentes nas teorias da adaptação, a fim de se referir aos objetos de estudos, Memórias de um rato de hotel e Muitos homens num só, livro e filme respectivamente.
} 


\section{Muitos homens num só: Dr. Antônio e João do Rio na telona}

Muitos homens num só (2015) é o primeiro longa-metragem de ficção da diretora Maria Izabel Kerti, mais conhecida como Mini Kerti, uma das mais requisitadas diretoras de publicidade e de videoclipes no Brasil. Além de estar à frente de diversas campanhas publicitárias, Mini Kerti também já dirigiu e foi roteirista de alguns documentários: Chame gente - 50 anos de trio elétrico (2002), Contratempo (2008), este dirigido junto com Malu Mader e Barão Vermelho - por que a gente é assim? (2017). As séries também estão no currículo da carioca que, em 2015, dirigiu Andre Midani Do vinil ao download e, em 2016, Minha Estupidez, ambos pela GNT; além disso, dirigiu alguns episódios da série Preamar (2011), produzida pela HBO, e, recentemente, também dirigiu e roteirizou alguns episódios da série Sob Pressão (2017-2018), exibida pela Rede Globo. Atualmente, Maria Izabel Kerti é diretora e sócia da Conspiração Filmes, está na direção do programa Superbonita da GNT desde 2015, e está trabalhando em dois documentários: uma para HBO sobre o músico Jorge Mautner, Kaos em Ação; e outro sobre a turnê do cantor Gilberto Gil, Refavela. ${ }^{7}$

Produzido pela Tambellini Filmes, com coprodução da TeleImage e do Canal Brasil e distribuído pela Downtown Filmes, Muitos homens num só foi exibido pela primeira vez no $18^{\circ}$ Cine PE Festival Audiovisual, realizado em Pernambuco no ano de 2014, sendo um dos filmes mais premiados do festival, totalizando dez prêmios: júri popular, melhor filme, direção (Mini Kerti), ator (Vladimir Brichta), atriz (Alice Braga), coadjuvante (Pedro Brício), roteiro (Leandro Assis), direção de arte (Kiti Duarte), trilha sonora (Dado Villa-Lobos) e edição de som (Thomas Alen). O filme tem trilha sonora composta por Dado Villa-Lobos, roteiro de Leandro Assis, Nina Crintz e Mini Kerti e conta com um elenco já consagrado, dentre eles, os já mencionados Vladimir Brichta (Dr. Antônio) e Alice Braga (Eva), além de Caio Blat (Félix Pacheco), Silvio Guindane (Barreto) e Luiz Carlos Miele (barão) ${ }^{8}$. Com um investimento estimado em R $\$ 3.370 .000^{9}$, Muitos homens num só estreou no cinema em 25 de junho de 2015, arrecadando uma bilheteria de 1.671 ingressos ${ }^{10}$.

Em seu livro Manual do roteiro: os fundamentos do texto cinematográfico (2001), Syd Field, autor de diversos livros sobre roteiro, declara que o "[r]oteiro é uma história contada

\footnotetext{
${ }^{7}$ Informações disponíveis em: < http://www.conspiracao.com.br/home\#/diretores/16/bio>. Acesso em: 20 jul. 2018.

${ }^{8}$ Disponível em: <http://oglobo.globo.com/cultura/muitos-homens-num-so-conquista-dez-trofeus-no-18-cine-pe12372165>. Acesso em: 30 out. 2016.

${ }^{9}$ Disponível em: <http://www.imdb.com/title/tt4224044/>. Acesso em: 30 out. 2016.

${ }^{10}$ Disponível em: <http://www.adorocinema.com/filmes/filme-228068/bilheterias/>. Acesso em: 30 out. 2016.
}

Revista Graphos, Vol. 20 n. 1, 2018 | UFPB/PPGL | ISSN 1516-1536 
em imagens, diálogo e descrição, localizada no contexto da estrutura dramática" (2001, p. 11). Dessa forma, o roteiro de um filme não lida somente com uma linguagem dramática, mas também com fotografias, sons, localizações específicas, marcações de tempo, etc., que constituem o meio audiovisual que é o filme.

A composição do roteiro final de Muitos homens num só surgiu com a junção de dois roteiros, um escrito pela diretora do filme, Mini Kerti, e outro escrito por Leandro Assis; o primeiro com visão mais romântica e o segundo com um caráter mais policial. Em 2008, Mini e Leandro se conheceram e decidiram juntar os dois roteiros, incorporando novas ideias que levaram à versão final do roteiro, assinada por Leandro Assis e Nina Crintzs ${ }^{11}$.

Já na abertura do filme Muitos homens num só o espectador fica sabendo que se trata de uma adaptação da obra de João do Rio, pois logo abaixo do título aparece a mensagem "Baseado na obra de João do Rio" (00:01:39); além disso, essa menção também é feita nos créditos finais, mostrando ao espectador algumas informações sobre o Dr. Antônio e as Memórias de um rato de hotel (01:26:52).

Evidentemente, o público deve notar que, mesmo sendo baseado na obra de João do Rio, o roteiro é criativo e não se confunde com o livro, portanto, também é original: "[a]daptar uma novela, livro, peça de teatro ou artigo de jornal ou revista para roteiro é a mesma coisa que escrever um roteiro original" (FIELD, 2001, p. 174). Em outras palavras, romance é um tipo de gênero e roteiro é outro. Sendo assim, mudanças na adaptação de um livro para um roteiro são inevitáveis, conforme foi discutido na seção anterior.

Segundo Mini Kerti, em uma entrevista para a autora deste trabalho, o projeto do filme Muitos homens num só nasceu depois do momento em que ela conheceu o livro Memórias de um rato hotel. Para a cineasta, é importante que as pessoas conheçam a obra de João do Rio, principalmente os cariocas, que, entrando em contato com a obra do cronista, podem entender e conhecer melhor as origens do Rio de Janeiro e "[o] que é ser carioca” (KERTI, 2016). Por conseguinte, é possível dizer que o roteiro da obra de chegada (o filme) mantém a essência da obra de partida (o livro), ao passo que conta uma parte das "memórias do Dr. Antônio", com alguns cortes e acréscimos como, por exemplo, a inserção de novos personagens.

Para recriar um Rio de Janeiro do início do século XX, foi necessário que a direção de arte investisse muito no trabalho de cenografia, fotografia e figurino, a fim de reproduzir os principais cenários frequentados pelo Dr. Antônio, pois, para entender esse personagem, também é necessário que haja uma compreensão do contexto em que o dândi viveu, a Belle

\footnotetext{
${ }^{11}$ Disponível em: <http://cinema.uol.com.br/noticias/reuters/2015/06/24/alice-braga-e-vladimir-brichta-estrelam-
} romance-policial-de-epoca.htm>. Acesso em: 30 out. 2016.

Revista Graphos, Vol. 20 n. 1, 2018 | UFPB/PPGL | ISSN 1516-1536 
Époque. Para ambientar essa atmosfera em que o Dr. Antônio agia, o trabalho de iluminação foi essencial, conforme descreve Mini Kerti em uma entrevista para o site AdoroCinema:

\begin{abstract}
O conceito principal da fotografia elaborada pelo Flávio Zangrandi foi usar muita luz de cena, luminárias e velas, no caso dos interiores à noite, e luz externa que entrava pelas janelas, no caso do interior de dia. Filmamos muitas cenas em silhueta, já que um ladrão trabalha sempre no escuro (KERTI, 2015, s/p) ${ }^{12}$.
\end{abstract}

De fato, o apuro técnico em relação à cenografia, fotografia e ao figurino de Muitos homens num só chamou a atenção da crítica. Para Francisco Russo, crítico de cinema brasileiro, a direção do filme foi muito feliz "[...] ao apostar na caracterização minuciosa da época retratada. Há um apuro técnico que chama a atenção, poucas vezes vista em filmes de época no cinema brasileiro, no sentido de replicar de forma convincente detalhes do figurino, direção de arte e cenários" (RUSSO, 2015, s/p) ${ }^{13}$.

Pode-se tomar como exemplo dessa qualidade técnica de cenografia e fotografia as cenas que se passam no interior dos hotéis de luxo em que Dr. Antônio se hospedava. Conforme a própria diretora do filme afirmou em uma citação anterior, houve um jogo de iluminação durante as cenas como, por exemplo, no instante em que o Dr. Antônio rouba os hóspedes de um hotel, dorme com uma prostituta e sai à paisana pela manhã (00:11:40). Nesse momento, ele estava agindo como um ladrão e para dar um tom mais obscuro, foi usada somente a iluminação de cena, praticamente à base de luz de velas; tal escolha é significativa, uma vez que o filme se passa em um momento em que o Brasil vivia a transição da luz de velas para as primeiras lâmpadas elétricas. Se as cenas internas têm uma paleta de cores mais escuras, foi feito o oposto nas cenas externas, as quais apresentam uma paleta de cores mais claras, evidenciando tons de azul, que lembram o mar do Rio de Janeiro como, por exemplo, na cena em que Dr. Antônio e Eva passeiam pelas ruas da cidade carioca (00:34:50).

Com efeito, todo esse conjunto de direção geral, roteiro e direção de arte do filme talvez não fosse bem-sucedido se não fosse o elenco. Mesmo o elenco sendo bem reduzido, a integração entre os atores, a experiência e a versatilidade foram fundamentais para que eles dessem vida aos personagens de João do Rio. Outro fato que merece destaque é que durante várias entrevistas a diretora e os roteiristas de Muitos homens num só deixaram claro que se inspiraram livremente na obra de João do Rio, em especial, nas Memórias de um rato de hotel.

\footnotetext{
${ }^{12}$ Disponível em: <http://www.adorocinema.com/noticias/filmes/noticia-114102/>. Acesso em: 30 out. 2016.

${ }^{13}$ Disponível em: <http://www.adorocinema.com/filmes/filme-228068/criticas-adorocinema/>. Acesso em: 30 out. 2016.
} 
No entanto, há no filme a inserção de outros personagens que fazem parte de outras obras do cronista carioca, a saber, os personagens Eva, Jorge e o casal de namorados que Eva e Guedes observam em um café luxuoso. A personagem Eva (interpretada por Alice Braga) e seu marido, Jorge (interpretado por Pedro Brício), são personagens adaptados da peça de teatro Eva, escrita por João do Rio no ano de 1915. Já o casal de namorados, que aparece no filme quase como uma "figuração de cena" em um café luxuoso (00:29:15), foi inspirado nos personagens de Rodolfo e Clotilde, do conto "Dentro da noite", publicado no livro de título homônimo, no ano de 1910, o qual João do Rio dedica a Félix Pacheco. É possível perceber que esse casal de namorados é inspirado nos personagens de Rodolfo e Clotilde por meio de uma fantasia criada por Dr. Antônio e Eva, na qual eles imaginam o homem espetando a mulher e, em seguida, "bebendo" o sangue que escorria dos braços de sua namorada (00:29:34). A trama de personagens não finda por aí, pois Félix Pacheco (interpretado por Caio Blat) também é um personagem do filme, bem como Barreto (interpretado por Silviano Guindade), personagem que representa João do Rio. Na próxima seção será discutida a relação desses personagens, Félix e Barreto, assim como a do Dr. Antônio, com o livro Memórias de um rato de hotel.

\section{Um espelho de duplos: João do Rio e Dr. Antônio}

Conforme foi discutido na primeira seção deste artigo, "Memórias de um rato de hotel: memórias de João do Rio ou Dr. Antônio?", há um mascaramento narrativo por detrás dessas memórias envolvendo a autoria do livro. Contudo, chegou-se à conclusão de que, dados os elementos históricos e bio-bibliográficos apurados pelos críticos, João do Rio seria realmente o autor do livro, posto que, segundo a teoria de Philippe Lejeune (2014), exposta na seção “As máscaras narrativas do texto", a escrita da obra deu-se de forma coletiva, sendo Arthur Antunes Maciel o "modelo" e João do Rio o "redator".

Sendo assim, se de certa forma, João do Rio está presente no livro Memórias de um rato de hotel, como o filme inspirado no livro adaptaria isso para o cinema? $\mathrm{Na}$ entrevista feita com a diretora de Muitos homens num só para a autora deste trabalho, ela afirma que o personagem Barreto é uma homenagem a João do Rio, pseudônimo de João Paulo Emílio Cristóvão dos Santos Coelho Barreto (KERTI, 2016). Dessa forma, a exemplo da crítica e dos pesquisadores, pode-se perceber que o filme também trata João do Rio como autor das 
memórias do Dr. Antônio, mas não somente pelo fato de apresentar um personagem jornalista que representa o cronista carioca.

Há no filme outros mascaramentos que remetem o espectador a João do Rio como, por exemplo, um pequeno detalhe de uma das primeiras cenas em que Dr. Antônio está roubando um quarto de hotel (00:04:25). Enquanto revirava o quarto sob a luz de um isqueiro, Dr. Antônio encontra o livro $O$ retrato de Dorian Gray, de Oscar Wilde, e abre em uma página qualquer. Mais adiante, o espectador vai perceber que o gatuno também roubou esse livro; isso acontece quando Eva entra no quarto do ladrão para deixar um bilhete para ele e encontra o livro em cima de um móvel (01:03:20). Este livro é uma referência direta a João do Rio, pois a edição de $O$ retrato de Dorian Gray utilizada pelo filme é justamente a primeira edição do livro traduzida pelo cronista carioca em 1919 e postumamente publicada em 1923.

Nessa lógica, Mini Kerti também considera que João do Rio e Dr. Antônio são muito parecidos, pois ambos têm uma alma observadora em relação às ruas cariocas, principalmente em relação às margens. Em um trecho do livro Memórias de um rato de hotel, Dr. Antônio rouba a carteira de uma mulher que estava no mesmo bonde que ele e, em vez de saltar do bonde, como de costume, decide colocar mais dinheiro dentro da carteira da senhora e a devolve para ela. Ele ficou observando a mulher e a descreveu da seguinte forma: "Era decerto uma mãe de família necessitada e eu tentara roubá-la... Como me doía a consciência se fizesse isso - eu que nunca roubei senão os que têm demais!” (RIO, 2015, p. 65). Nessa passagem, como em tantas outras presentes na narrativa, Dr. Antônio mostra a sua capacidade de solidariedade, observação e imaginação em relação à cidade e aos seus cidadãos.

No filme, essas cenas de observação das ruas também são frequentes, ainda mais quando Dr. Júlio Guedes, nome com que Arthur Antunes Maciel se apresenta no "Hotel dos Estrangeiros", mostra as ruas do Rio de Janeiro para Eva, que também é uma personagem observadora, posto que ela retrata as pessoas em seus desenhos. Nessas cenas, o Dr. Júlio Guedes leva Eva para perambular, refletir e observar pelas ruas, instigando-a a imaginar o que as pessoas que eles observam fazem da vida. A primeira "descrição" feita por Guedes é de um casal, em que ele fantasia que os dois viveriam um relacionamento estranho, pois para ele o homem era um espetador (referência ao conto "Dentro da noite", de João do Rio). Dessa forma, a lábia encantadora do gatuno faz com que Eva também imagine cenas do casal e, assim, os dois começam a descrever o que imaginam sobre algumas pessoas que encontram pelas ruas (00:29:10). 
Muitos homens num só também apresenta um recurso muito utilizado no cinema, a voz sobreposta, mais conhecida como voice-over. De acordo com o Dicionário teórico e crítico de cinema, de Jacques Aumont e Michel Marie, “[a] voz é a manifestação sonora do corpo do ator, mesmo que ele não esteja representado visualmente" (AUMONT; MARIE, 2003, p. 300). Dessa forma, a voz sobreposta reproduz a ação de um narrador e pode ser, por exemplo, a voz de um personagem da história contando o que está pensando, estabelecendo um diálogo direto com o espectador.

Quem faz essa voice-over do filme é o protagonista, o próprio Dr. Antônio, em cenas em que ele decide expor seu pensamento em relação a alguma situação, como por exemplo, na cena em que ele decide pedir desculpas a Eva durante o café da manhã e a convida para sair. Enquanto o ladrão está puxando a cadeira da mesa para que Eva se levante, há uma voz sobreposta, a voz dele, dizendo o que está se passando pela sua cabeça naquele momento: “A mulher infeliz é um perigo, está sempre pronta para uma pequena tolice” (00:45:55). Lembremos que há também no livro esses momentos em que Arthur Antunes Maciel, o narrador da história, expõe seus pensamentos e seu senso de criticidade em relação à sociedade, como por exemplo, no momento em que ele se apaixona por Etelvina, mas não queria que essa paixão virasse amor:

\footnotetext{
Fatalmente, não esquecia Etelvina. Ela morava na rua dos Inválidos ${ }^{\circ} 52$. Eu, como lhe tinha muita simpatia, receava aproximar-me. Se virasse amor? Poderia esconder toda vida a minha profissão? Então, procurava aturdir-me no exercício de trabalhos ou em prazeres. Gastava assim enormemente. Só poderia passar despercebido numa cidade como o Rio um homem gastando que eu gastava em carros, hotéis, mulheres e teatros - naquela época, que era a do Encilhamento (RIO, 2015, p. 37).
}

Além disso, pode-se afirmar que o espelhamento duplo entre João do Rio e Dr. Antônio se dá, especialmente, pela questão do olhar, do observar, conforme o que foi dito por Mini Kerti. Paulo Barreto ficou famoso por descrever as ruas cariocas do início do século XX, circulando por histórias da mais alta elite até o espaço marginal das ruas, sendo que mostrou um grande fascínio por este último. Tanto Dr. Antônio quanto João do Rio circulavam por esses dois ambientes da cidade, a elite e a margem. No entanto, Paulo Barreto e Arthur Antunes Maciel não se aproximam somente por serem dois dândis que gostavam de observar as ruas, mas também por serem sujeitos com uma identidade fragmentada, tendo em vista que João do Rio é só um dos muitos pseudônimos utilizados por Paulo Barreto, que além de escritor também foi jornalista, teatrólogo e crítico; Dr. Antônio, tampouco, era o único pseudônimo utilizado por Arthur. 
Com efeito, é possível afirmar que a escolha de como trabalhar com a temática da identidade no filme foi muito inteligente, pois além de apresentar os problemas de personalidade vividos por Arthur Antunes Maciel na obra de partida, a obra de chegada acrescentou o personagem Félix Pacheco na história, o que também deixou o filme com um caráter mais policial. Além disso, a versatilidade identitária também está presente no título da adaptação que, primeiramente, foi submetido na plataforma da ANCINE ${ }^{14}$ como 20 Homens num só e uma Mulher de 20, fazendo uma clara alusão, na primeira parte, ao capítulo VI das Memórias de um rato de hotel, "Vinte homens num só"; e na segunda parte, faz alusão à peça de teatro Eva. Contudo, a denominação final muito corrobora com as questões identitárias do Dr. Antônio, que era, de fato, 'muitos homens num só'.

Em Memórias de um rato de hotel, Arthur questiona a todo momento sua dupla personalidade, colocando a culpa do seu 'mau caráter' em Dr. Antônio. Em um desses momentos, ele afirma que deveria ser estudado por um psiquiatra:

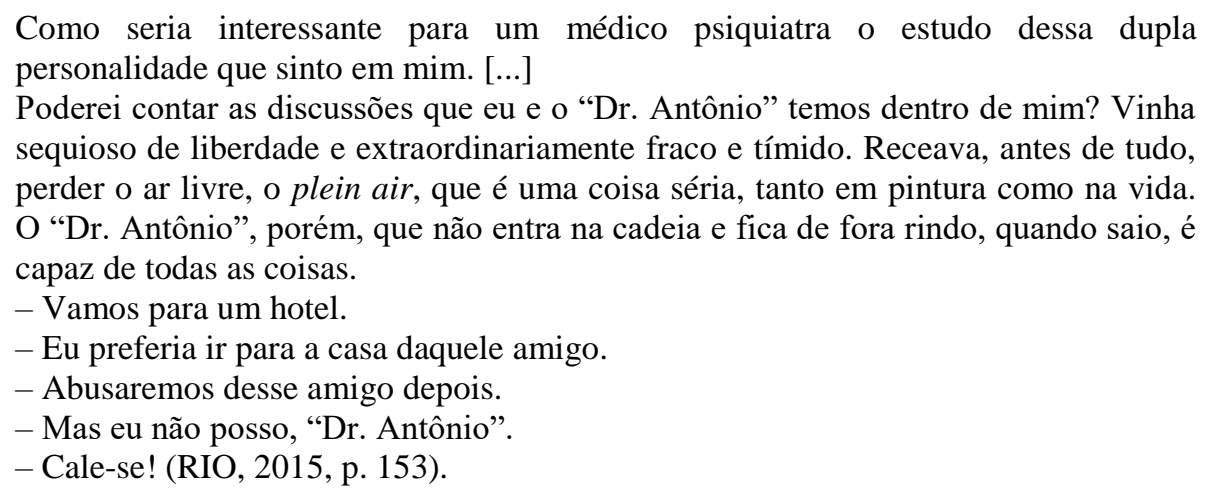

No excerto acima é possível notar que Arthur e Dr. Antônio estão discutindo, ou seja, as duas personalidades de Arthur estão tendo um embate, mas Dr. Antônio acaba vencendo, como sempre. No filme, além da utilização do recurso de voice-over para representar esses momentos de reflexão, há também cenas em que o próprio Arthur coloca em xeque a identidade do Dr. Antônio como, por exemplo, na cena em que este vai ao encontro de Vellez para lhe entregar os títulos de banco que roubou do barão que estava hospedado no mesmo hotel que ele. Nessa cena, Arthur diz a Vellez que sua vida é uma mentira, que foi construída com a ajuda do amigo, mas Vellez afirma ao gatuno: "Sua vida é fantástica, você é o

\footnotetext{
${ }^{14}$ Informações disponíveis em: <http://sif.ancine.gov.br/projetosaudiovisuais/ConsultaProjetosAudiovisuais.do;jsessionid=E4DD774CDD0AD3 E28027C1B75EA68170?method=detalharProjeto\&numSalic $=060367$ >. Acesso em: 20 jul. 2018. Revista Graphos, Vol. 20 n. 1, 2018 | UFPB/PPGL | ISSN 1516-1536
} 
Dr. Antônio!"; após essa fala, a câmera foca no rosto de Arthur, que dá um sorriso irônico e questiona: “Quem é o Dr. Antônio?” (01:07:10).

Dessa maneira, a identidade de Arthur Antunes Maciel é a de uma vida marginal, pois mesmo ele sendo um dândi e frequentando os melhores hotéis, cafés e teatros, o gatuno sempre estará à margem da sociedade; e ainda que Arthur tente mudar de vida, como no momento em que tenta fugir com Eva, a personalidade do Dr. Antônio sempre falará mais alto, uma vez que, mesmo com a identificação das impressões digitais, o ladrão arranja uma maneira de continuar com seu trabalho.

Outrossim, a personagem de Eva também vive, durante o filme, alguns dilemas com sua identidade. Em uma das primeiras cenas, durante o jantar no "Hotel dos Estrangeiros", enquanto Eva observa e desenha Dr. Antônio, há alguns questionamentos que o Dr. Júlio Guedes faz sobre a identidade de Eva. Primeiramente, ele a elogia, dizendo que é uma artista e que deveria viver da sua arte, mas é interrompido pelo marido de Eva, Jorge, que diz que é muito vulgar para sua mulher trabalhar e que os desenhos são só uma distração.

Assim, o Dr. Guedes faz uma interpretação sobre a identidade que ele acredita ser a de Eva: à primeira vista, o gatuno acredita na ideia passada por Jorge, de que Eva era uma mulher feliz com o casamento e não ansiava por ter sua própria casa para cuidar dos filhos e do marido; tanto que ele supõe que ela era uma moça de família rica que estudou em colégio de freiras, lia romances franceses e sonhava que sua vida fosse como um desses romances franceses. Acontece que, um dia, sua mãe resolveu que ela deveria se casar com um homem mais rico ainda, assim ela conheceu Jorge, e após o casamento, os dois entraram para a vida social do Rio de Janeiro (00:22:20).

Contudo, essa identidade de boa esposa que Eva passava para a sociedade é descontruída ao longo do filme com a ajuda do Dr. Guedes. Vale lembrar que ainda no início do século XX, a sociedade conservadora considerava vulgar uma mulher trabalhar fora de casa, pois ela deveria construir uma família e viver para cuidar do marido, dos filhos e da casa. Eva demonstra não estar contente com seu casamento, o gatuno percebe essa infelicidade e a leva para fora do hotel, para andar pelo Rio de Janeiro e ver o mar; por sinal, ela tinha muita vontade de conhecer o mar, mas seu marido ainda não lhe tinha apresentado. A partir do momento em que Eva se envolve com o Dr. Guedes, ela conhece a liberdade, e isso se reflete em seu visual: nas primeiras cenas, ela aparece com o cabelo preso, e, no decorrer do filme, à medida que ela vai se libertando da prisão que é seu casamento, ela vai 
usando o cabelo mais solto, o que indica liberdade. Dessa forma, ao final do filme, Eva aparece em Paris, livre de seu casamento e vivendo de sua arte.

Evidentemente, Félix Pacheco também é um dos "construtores de identidade" do filme. Félix Pacheco e João do Rio, apesar de discordarem em alguns pensamentos, eram amigos e até chegaram a trabalhar juntos durante um tempo em um jornal. Mini Kerti confirmou que a inserção no filme do personagem histórico Félix Pacheco, que além de jornalista também era poeta, "foi puramente pela questão policial", posto que ele foi o fundador do Gabinete de Identificação e Estatística da Polícia do Distrito Federal, atualmente conhecido como Instituto Félix Pacheco ${ }^{15}$, havendo, assim, um fundo de importância histórica por trás dessa questão de gênero "puramente policial". No filme, enquanto o personagem de Barreto defende o rato de hotel, chamando-o de inteligentíssimo, o personagem de Félix Pacheco quer identificar o tal do "Dr. Antônio", e até consegue imprimir as digitais do gatuno; de fato, ele acredita que, assim, o Dr. Antônio deixaria de "trabalhar", visto que toda vez que houvesse um roubo, a identidade do ladrão poderia ser descoberta por meio de suas digitais.

Por fim, após ser preso, o Dr. Antônio recebe a visita de Barreto na casa de detenção. Nesse momento, não faltam elogios de Barreto para o Dr. Antônio, pois o jornalista expressa sua admiração pelo "rato de hotel" dizendo que mesmo que este seja um ladrão, o considera inteligentíssimo. Faz assim uma referência ao artigo "O representativo do roubo inteligente", escrito por João do Rio em 1911, no qual, através de muita ironia, o cronista carioca considera o Dr. Antônio como um dos mais inteligentes ladrões do crime brasileiro: "Quando se chega então a ser o Dr. Antônio [...] o grande crime é não continuar. Que seria do nome Brasil, país tão abundante em representativos, se lhe viesse a faltar o representativo aos anais da mais ousada e inteligente das profissões? Era uma falha imperdoável [...]” (RIO, 2015, p. 179-180).

\section{Considerações finais}

Diante do exposto, fica patente a importância literária e histórica do livro Memórias de um rato de hotel (1912), cuja autoria é creditada a João do Rio. Importância histórica porque retrata um período muito interessante da história brasileira, a Belle Époque, momento em que o Brasil começava sua modernização e pagava por tal transformação altos custos sociais. Além disso, traz à tona a história de Arthur Antunes Maciel, um ladrão que "nasceu junto com a República" e sob a alcunha de "Dr. Antônio" e ficou muito conhecido no início do século

\footnotetext{
${ }^{15}$ Disponível em: <http://www.academia.org.br/academicos/felix-pacheco/biografia>. Acesso em: 02 nov. 2016. Revista Graphos, Vol. 20 n. 1, 2018 | UFPB/PPGL | ISSN 1516-1536
} 
XX por aplicar golpes em hotéis de luxo do Brasil, principalmente no Rio de Janeiro, chegando a se hospedar em mais de cinco hotéis ao mesmo tempo.

Memórias de um rato de hotel também é considerada uma obra relevante para a literatura brasileira, não somente pelo fato de ser creditada ao renomado escritor carioca João do Rio, mas também pelo fato de o autor fazer um jogo com o leitor na medida em que ele molda essas memórias como se fossem realmente uma autobiografia, algo que merece atenção, pois o título do texto-fonte, Memórias de um rato de hotel: o doutor Antônio narra a sua vida, já sugere, por meio de um ardil ficcional, que o Dr. Antônio seja o autor das memórias. No entanto, conforme foi abordado no início deste artigo, há na própria narrativa das Memórias de um rato de hotel indícios de que a autoria seja de João do Rio, posto que o Dr. Antônio seria o que Philippe Lejeune (2014) chama de "modelo", ao passo que João do Rio seria o "redator" das memórias, o que o caracteriza como o verdadeiro autor.

Por sua vez, a adaptação cinematográfica Muitos homens num só (2015), dirigida por Mini Kerti, baseada na obra de João do Rio, contribuiu para que a história do Dr. Antônio não ficasse "perdida" por muitos anos novamente. De acordo com a diretora da adaptação, além da importância artística e histórica que seu primeiro longa-metragem representa, o filme também é uma homenagem a João do Rio, haja vista que traz personagens de outras obras do cronista carioca, os quais interagem com a história das Memórias de um rato de hotel.

Por fim, pode-se dizer que este trabalho cumpriu o objetivo de analisar e comparar as obras Memórias de um rato de hotel e Muitos homens num só, ressaltando o mascaramento narrativo utilizado na obra de partida, o qual também se refletiu na obra de chegada. Da mesma forma, foram estudados o contexto de produção e a estética de João do Rio e Mini Kerti, bem como as relações entre a linguagem fílmica e a literária.

\section{Referências}

ACADEMIA brasileira de letras. Félix Pacheco: biografia. Disponível em:

<http://www.academia.org.br/academicos/felix-pacheco/biografia>. Acesso em: 02 nov. 2016.

ADOROCINEMA. Muitos homens num só: bilheteria. Disponível em: <http://www.adorocinema.com/filmes/filme-228068/bilheterias/>. Acesso em: 30 out. 2016.

Retrospectiva 2015: as 30 maiores bilheterias do cinema brasileiro. Disponível em: <http://www.adorocinema.com/slideshows/filmes/slideshow-118218/\#30>. Acesso em 04 nov. 2016. 
ALMEIDA, Carlos Helí de. Muitos homens num só conquista dez troféus no $18^{\circ}$ Cine PE: drama de época dirigido por Mini Kerti é inspirado em personagens do cronista João do Rio. Disponível em: <http://oglobo.globo.com/cultura/muitos-homens-num-so-conquista-deztrofeus-no-18-cine-pe-12372165>. Acesso em: 30 out. 2016.

ANCINE. Consulta de Projetos Audiovisuais: Muitos Homens Num Só (Ex - 20 Homens Num Só e uma Mulher de 20). Disponível em:

$<$ http://sif.ancine.gov.br/projetosaudiovisuais/ConsultaProjetosAudiovisuais.do;jsessionid=E4 DD774CDD0AD3E28027C1B75EA68170? method=detalharProjeto\&numSalic $=060367>$. Acesso em: 20 jul. 2018.

AUMONT, Jacques; MARIE, Michel. Dicionário teórico e crítico de cinema. Tradução: Eloisa Araújo Ribeiro. São Paulo: Papirus, 2003.

BAZIN, André. O Cinema: ensaios. Tradução: Eloisa de Araújo Ribeiro. São Paulo: Brasiliense, 1991.

CARVALHAL, Tania Franco. Literatura Comparada. 3. ed. São Paulo: Ática, 1998.

CLÜVER, Claus. Inter textus / inter artes / inter media. Tradução: Elcio L. Cornelsen et al. In: Aletria: Revista de estudos de literatura. Belo Horizonte: CEL, FALE, Universidade Federal de Minas Gerais, n. 14, p. 11-41, jul.-dez. 2006. Disponível em:

<http://www.periodicos.letras.ufmg.br/index.php/aletria/article/viewFile/1357/1454>. Acesso em: 8 jun. 2016.

CONSPIRAÇÃO. Mini Kerti. Disponível em:

<http://www.conspiracao.com.br/home\#/diretores/16/bio>. Acesso em: 20 jul. 2018.

FIELD, Syd. Manual do roteiro: os fundamentos do texto cinematográfico. Tradução: Álvaro Ramos. 14. ed. Rio de Janeiro: Objetiva, 2001.

HALL, Stuart. Quem precisa de identidade? In: SILVA, Tomaz T. (Org.). Identidade e diferença: a perspectiva dos estudos culturais. Rio de Janeiro: Vozes, 2004.

HUTCHEON, Linda. Uma teoria da adaptação. Tradução: André Cechinel. 2. ed. Florianópolis: Editora da UFSC, 2013.

IMDB. Muitos homens num só (2014). Disponível em:

<http://www.imdb.com/title/tt4224044/>. Acesso em: 30 out. 2016.

KERTI, Maria Izabel. Entrevista com a diretora do filme Muitos homens num só: depoimento. [dezembro, 2016]. Pato Branco - PR: O encontro de João do Rio e Dr. Antônio em Memórias de um rato de hotel e Muitos homens num só: diálogos entre cinema e literatura. Entrevista concedida a Carla Helena Lange. Disponível em:

<http://repositorio.roca.utfpr.edu.br/jspui/bitstream/1/7947/1/PB_COLET_2016_2_05.pdf>. Acesso em: 28 maio 2018.

LANGE, Carla Helena. O encontro de João do Rio e Dr. Antônio em Memórias de um rato de hotel e Muitos homens num só: diálogos entre cinema e literatura. 2016. 49 f. Monografia (Graduação em Letras Português e Inglês) - Universidade Tecnológica Federal do Paraná, Pato Branco, 2016. Disponível em: 
<http://repositorio.roca.utfpr.edu.br/jspui/bitstream/1/7947/1/PB_COLET_2016_2_05.pdf>. Acesso em: 28 maio 2018.

LEJEUNE, Philippe. O pacto autobiográfico: de Rousseau à internet. Tradução de Jovita Maria Gerheim Noronha e Maria Inês Coimbra Guedes. 2. ed. Belo Horizonte: Editora da UFMG, 2014.

MEMÓRIAS de um rato de hotel: o Dr. Antônio narra sua vida. Gazeta de Notícias. Rio de Janeiro, 24 dez. 1911. Disponível em:

$<$ http://memoria.bn.br/DocReader/DocReader.aspx?bib=103730_04\&pesq=rato $\% 20 \mathrm{de} \% 20 \mathrm{ho}$ tel>. Acesso em: 20 jul. 2018.

MUITOS homens num só. Direção: Mini Kerti. Produção: Mini Kerti e Flávio Ramos Tambellini. Intérpretes: Vladimir Brichta; Alice Braga; Caio Blat; Silvio Guindane; Pedro Brício, e outros. Roteiro: Leandro Assis e Nina Crintzs. Rio de Janeiro: Tambellini Filmes, 2015, 92 min., son., color., 35mm. Disponível em: <https://itunes.apple.com/br/movie/muitoshomens-num-so/id1076035625>. Acesso em: 10 abr. 2016.

PLAZA, Julio. Tradução intersemiótica. 2. ed. São Paulo: Perspectiva, 2010.

RIO, João do. Memórias de um rato de hotel. 3. ed. Rio de Janeiro: Dantes, 2015.

Eva. In: BETING, Graziella (org.). Coleção João do Rio: crônica, folhetim e teatro. São Paulo: Carambaia, 2015.

Dentro da noite. In: LEVIN, Orna Messer (org.). João do Rio: antologia de contos. São Paulo: Lazuli Editora; Companhia Editora nacional, 2010.

RODRIGUES, João Carlos. João do Rio: vida, paixão e obra. Rio de Janeiro: Civilização Brasileira, 2010.

RUSSO, Francisco. Entrevista exclusiva: diretora de Muitos homens num só revela que se inspirou em filme de Hitchcock. Disponível em:

<http://www.adorocinema.com/noticias/filmes/noticia-114102/>. Acesso em: 30 out. 2016.

STAM, Robert. Teoria e prática da adaptação: da fidelidade à intertextualidade. Ilha do Desterro, Florianópolis, n. 51, p. 019-053, jul./dez. 2006. Disponível em:

<https://periodicos.ufsc.br/index.php/desterro/issue/view/653>. Acesso em: 1 abr. 2016.

ZAVALA, Rodrigo. Alice Braga e Vladimir Brichta estrelam romance policial de época. Disponível em: <http://cinema.uol.com.br/noticias/reuters/2015/06/24/alice-braga-e-vladimirbrichta-estrelam-romance-policial-de-epoca.htm>. Acesso em: 30 out. 2016.

Recebido em 16/06/2018

Aceito para publicação em 27/07/2018 